\title{
Processing of Back Surface of Si Wafers With a Pulsed Nd:YAG Laser
}

\author{
Neng Liu, Jonathan Vincent, Khalid Moumanis and Jan J. Dubowski \\ Laboratory for Quantum Semiconductors and Photon-based BioNanotechnology, Interdisciplinary Institute for Technological \\ Innovation (3IT), CNRS UMI-3463, Université de Sherbrooke, Sherbrooke, 3000, boul. de l'Université, Québec, J1K 0A5, \\ Canada
}

Electronic mail: jan.j.dubowski@usherbrooke.ca

\begin{abstract}
Silicon ( $\mathrm{Si}$ ) is a widely used material by the very-large-scale integration technology addressing manufacturing of integrated electronic circuits. Micromachined Si has also shown its advantages in the fabrication of advanced microelectronic, photonic and micro-electro-mechanical system devices whose continuously decreasing dimensions present growing challenges in packaging. In that context, we have investigated an Nd:YAG laser based process for micromachining of back surface of Si (100) wafers. The application of a laser for micromachining brings the advantage of a selective area processing, while the Nd:YAG laser holds the promise of a cost attractive solution. Our experimental results, consistent with temperature simulations, demonstrate that it is possible to melt the back surface of $380 \mu \mathrm{m}$ thick $\mathrm{Si}$ wafers with $100 \mu \mathrm{m}$ diameter laser pulses of energy between 2.6 and $3.2 \mathrm{~mJ} /$ pulse. Microscopic images and profilometry scans have indicated no measurable modification of the front surface of laser-irradiated wafers. Fourier transform infrared absorption spectroscopy data have indicated formation of a porous $\mathrm{Si}$ material on the back surface of irradiated wafers that could be dissolved relatively easily in a potassium hydroxide solution.
\end{abstract}

DOI: $10.2961 / \mathrm{jlmn} .2016 .02 .0014$

Keywords: Nd:YAG laser, silicon, COMSOL, back surface processing, FTIR

\section{Introduction}

Laser processing of silicon $(\mathrm{Si})$ has attracted growing attention due to the great potential of this material in the fabrication of micro-electro-mechanical systems (MEMS) [1], opto-electronic devices such as solar cells [2], metal-onsemiconductor (MOS) devices [3,4] as well as biosensing devices [5-9]. For instance, so called infrared (IR) laser $(\lambda=1940 \mathrm{~nm})$ transmission bonding process of Si wafers has been developed as an attractive method of wafer level bonding applied in MEMS packaging [10]. The unique characteristic of the laser is its ability to deliver heat in a localized zone, which reduces the potential for excessive heating of some elements in processed architectures $[11,12]$. It has been reported that in comparison to standard bonding techniques, the strength of a so called laser transmission bonding process could be improved by $50 \%$ [10].

The transmission of IR lasers through $400 \mu \mathrm{m}$ thick Si wafer increases from near $0 \%$ to $50 \%$ with wavelength increasing from 1000 to $1500 \mathrm{~nm}$ [13]. This feature has found application in the development of a stealth dicing technology where an Nd:YAG laser $(\lambda=1064 \mathrm{~nm})$ is focused below the surface of a $\mathrm{Si}$ wafer to create cracks that promote dicing during the separation step [14]. Because the stealth dicing process is dry and clean $[11,12]$, it has become a powerful tool in dicing of devices fabricated on Si wafers [15]. Goldcoated back surface of $\mathrm{Si}$ has been successfully processed with a $1940 \mathrm{~nm}$ laser, which allowed bonding two Si wafers
[10]. Also, experiments with a femtosecond (fs) laser $(\lambda=1550 \mathrm{~nm})$ have demonstrated that nonlinear absorption of $\mathrm{Si}$ allows carrying out structural modification of its back surface and fabrication of grooves with a post-processing etching step [16]. Processing of back surface of Si with a fundamental radiation of an Nd:YAG laser $(\lambda=1064 \mathrm{~nm})$ is not trivial due to the weak absorption of this irradiation by $\mathrm{Si}$ at room temperature $\left(\alpha \sim 9.61 \mathrm{~cm}^{-1}\right)$. However, the non-linear absorption coefficient of $\mathrm{Si}$ that increases to $\alpha \sim 7.61$ $\mathrm{x} 10^{5} \mathrm{~cm}^{-1}$ at $1700 \mathrm{~K}$, i.e., a melting point of this material [17], suggests that it should be possible to process back surface of $\mathrm{Si}$ wafers with that laser. The potential advantage of using Nd:YAG laser for such a process is a lower cost of ownership and operation in comparison to that of an fs laser.

In this study, we have investigated the feasibility of $\mathrm{Nd}$ :YAG laser induced modification of the back surface of Si wafers. Computer modeling of the conditions required to reach the melting point at the back surface of a $380 \mu \mathrm{m}$ thick wafer was verified experimentally by studying morphological and chemical changes of the processed material using surface profilometry, optical microscopy, Fourier transform infrared (FTIR) spectroscopy and scanning electron microscopy (SEM) techniques.

\section{Experiment}


A series of $10 \mathrm{~mm} \times 10 \mathrm{~mm}$ samples were selected from a commercially available $380 \mu \mathrm{m}$ thick p-type (Boron doped) Si (100) wafer (WRS Materials, San Jose, USA). The wafer was double side polished and its resistivity was $1 \sim 10 \Omega \mathrm{m}$. To remove surface contaminants, the samples were cleaned with Opticlear, acetone and isopropyl alcohol, each for 5 minutes. The roughness $\left(\sigma_{\mathrm{RMS}}\right)$ of the cleaned $\mathrm{Si}$ sample, as measured by AFM, was around $0.56 \mathrm{~nm}$.

The irradiation of $\mathrm{Si}$ samples was carried out in air by focusing an Nd:YAG laser $(\lambda=1064 \mathrm{~nm})$ beam on the back surface of samples using a $225 \mathrm{~mm}$ focal length lens with a focusing angle of $0.32 \mathrm{rad}$, which gave a $100 \mu \mathrm{m}$ diameter spot on the sample. The full width at half maximum (FWHM) of a Gaussian shape beam, as determined with a Si photo-diode (Thorlabs, DET2-SI), was 112 ns. The laser operating at $10 \mathrm{~Hz}$ delivered pulses of energy ranging between $2.6-3.2 \mathrm{~mJ} /$ pulse. The samples were irradiated with 10 pulses as $1 \mathrm{~s}$ was the minimum reaction time to control the laser shutter with a homemade control system. The samples' positions were changed by a computer controlled X-Y-Z stage with a step resolution of $10 \mu \mathrm{m}$.

The macro surface morphology of the $\mathrm{Si}$ wafer was imaged by a microscope (NIKON, Eclipse ME 6000L) and investigated by a profilometry technique (Dektak 150). Cross sections of samples were examined using a scanning electron microscope (SEM) (Supra 55 VP, Zeiss).

The laser-modified material was analyzed using a Hyperion 2000 IR microscope coupled to a Vertex 70v FTIR spectrometer (Bruker Optics) operating in a transmission mode.

\section{Modeling}

\subsection{One pulse irradiation}

The back surface temperature was estimated by analyzing heat transfer partial differential equation (PDE) using COMSOL software. The heat transfer PDE equation is expressed as [18]:

$$
\mathrm{Q}-\nabla(\mathrm{k}(\mathrm{T}) \nabla \mathrm{T})=\rho \mathrm{C} \frac{\partial \mathrm{T}}{\partial \mathrm{t}}
$$

with the inward heat source $Q$ defined as:

$$
Q=(1-R) \alpha F P(t) e^{-\alpha z} G(r)
$$

where $\rho$ : material density; $C$ : specific heat; $k$ : thermal conductivity; $F$ : laser fluence; $P(t)$ : temporal pulse shape $\left(\int_{0}^{\infty} \frac{P(t)}{t_{\ell}} d t=1\right), t_{\ell}$ is the pulse duration; $G(r)$ : spatial laser beam shape, e.g. circular Gaussian beam is $G(r)=$ $\exp \left(-\frac{2 r^{2}}{w_{0}^{2}}\right) ; \mathrm{w}_{0}$ : beam waist at the sample; $r$ : beam radius coordinate; $z$ : direction into the material; $T$ and $t$ : temperature and time, respectively. The melting point of $\mathrm{Si}$ is $1690 \mathrm{~K}$. The values of material density $(\rho)$, specific heat $(C)$, and thermal conductivity $(k)$ of solid and molten $\mathrm{Si}$ are shown in Table 1.

The absorption coefficient of molten $\mathrm{Si}$ is $7.61 \times 10^{5} \mathrm{~cm}^{-1}$ [19], and the temperature dependent absorption coefficient $(\alpha)$ of Si before melting, has been approximated with the following equation [20]:

$$
\alpha=12.991 \times \exp (0.0048244 \times T)-52.588 \times
$$

$\exp (-0.0002262 \times T)$

Table 1 Material constants, according to [21], used in COMSOL multiphysics simulation

\begin{tabular}{cll}
\hline & Solid silicon & Molten silicon \\
\hline$\rho\left(\mathrm{kg} / \mathrm{m}^{\wedge} 3\right)$ & 2320 & 2500 \\
$C(\mathrm{~J} /(\mathrm{kg} * \mathrm{~K}))$ & 710 & 680 \\
$k(\mathrm{~W} /(\mathrm{m} * \mathrm{~K}))$ & 148 & 200 \\
\hline
\end{tabular}

Fig. 1 (a) shows a 2D temperature distribution inside of a $\mathrm{Si}$ wafer (for the clarity shown is only a bottom $110 \mu \mathrm{m}$ thick slab) irradiated with a $3.2 \mathrm{~mJ}$ pulse focused on the back surface $(Z=0)$ to a $100 \mu \mathrm{m}$ diameter spot. Fig. 1 (b) illustrates the $1 \mathrm{D}$ temperature along $Z$ axis (laser irradiation direction) when the wafer is irradiated with a $3.2 \mathrm{~mJ}$ pulse focused on the back surface (solid line) and in the plane shifted by $0.01 \mathrm{~mm}$ towards the laser (dashed line). These results illustrate that achieving a desired temperature on the back surface of the irradiated wafer depends strongly on the precision in controlling the position of a focal plane. The shift of the focal plane to $Z=0.01 \mathrm{~mm}$ results in the surface temperature being reduced from $1960 \mathrm{~K}$ to $1600 \mathrm{~K}$, while the maximum temperature of $1630 \mathrm{~K}$ is generated at the focal plane.
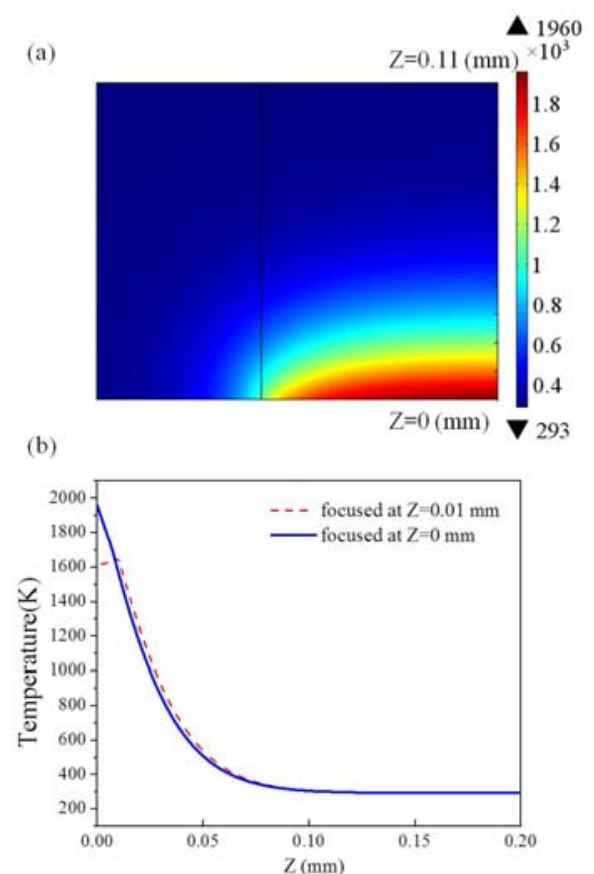

Fig. $12 \mathrm{D}$ temperature distribution inside of a Si wafer irradiated with a $3.2 \mathrm{~mJ} /$ pulse focused $(100 \mu \mathrm{m}$ spot $)$ on the back surface of the wafer (a), and temperature profiles along $\mathrm{Z}$ axis for the $\mathrm{Nd}$ :YAG laser focused on the back surface (solid line) and focused at $\mathrm{Z}=$ $0.01 \mathrm{~mm}$ (dash line). 
JLMN-Journal of Laser Micro/Nanoengineering Vol. 11, No. 2, 2016

Temporal plots of the Si back surface temperature induced with laser pulses from 2.0 to $3.6 \mathrm{~mJ}$ are shown in Fig. 2. These results indicate that to reach a melting point of the wafer, it has to be irradiated with a pulse energy of $\sim 2.8 \mathrm{~mJ}$. The duration time of $\mathrm{Si}$ in the molten phase increases with pulse energy, and for a $3.6 \mathrm{~mJ} /$ pulse it reaches $200 \mathrm{~ns}$. As the temperature of the Si front surface is practically unaffected by the laser, we assumed in our calculations that its reflectivity remained at 0.3 [22]. The refractive index changes when the solid phase $\mathrm{Si}$ is molten by laser heating [20], which corresponds to an estimated increase of the back surface reflectivity by $10 \%$. However, as the absorption coefficient of molten $\mathrm{Si}$ is around $7.6 \times 10^{5} \mathrm{~cm}^{-1}$, most of the laser energy is absorbed by this phase Si. Furthermore, we find that the reflectivity at the interface of solid and molten $\mathrm{Si}$ is very weak (0.002), so the reduction of absorbed energy due to formation of this interface is negligible. Therefore, no obvious breaking is observed in the otherwise monotonic behavior of time dependent temperature of the $\mathrm{Si}$ back surface, which is in contrast to the results of laser induced melting of the Si front surface [21].

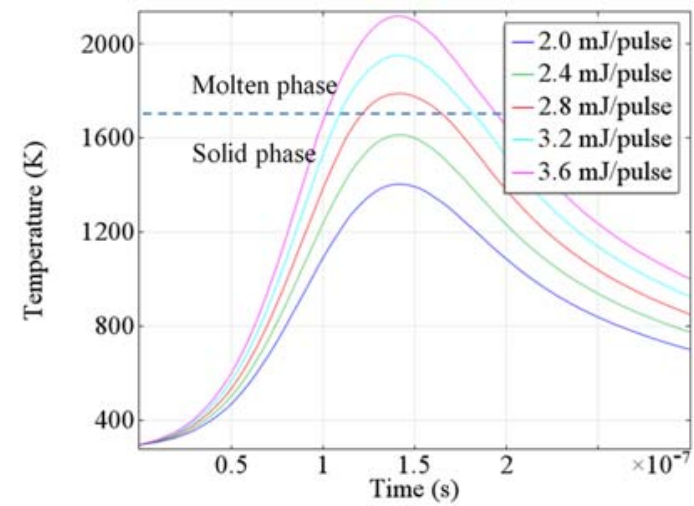

Fig. 2 Temporal plots of the Si back surface temperature induced with $112 \mathrm{~ns}$ laser pulses of energy between 2.0 and $3.6 \mathrm{~mJ} / \mathrm{pulse}$ (100 $\mu \mathrm{m}$ spot diameter)

Table 2 shows temperatures of the back surface of the irradiated $\mathrm{Si}$ wafer for selected times elapsed from the onset of the irradiation. A slow decay of the temperature is evident, especially after $1 \mu \mathrm{s}$ from the onset of the irradiation. For instance, for the wafer irradiated with a $3.6 \mathrm{~mJ} /$ pulse, it takes $6 \mathrm{~ms}$ for the back surface of the wafer drop to $370.8 \mathrm{~K}$, while the temperature of a wafer irradiated with a $2.0 \mathrm{~mJ} / \mathrm{pulse}$ remains at $339.0 \mathrm{~K}$ for the same time elapsed from the onset of the irradiation. This increased temperature of the wafer will contribute to the maximum temperature induced by a consecutive pulse.
Table 2 Back surface temperature vs. time when irradiated by one pulse Nd:YAG laser from 2.0 to $3.6 \mathrm{~mJ} /$ pulse

\begin{tabular}{llllll}
\hline $\begin{array}{l}\text { Pulse } \\
\text { energy } \\
(\mathrm{mJ} / \text { pulse })\end{array}$ & $\begin{array}{l}\mathrm{T}_{\max }(\mathrm{K}) \\
(140 \mathrm{~ns})\end{array}$ & $\begin{array}{l}\mathrm{T}(\mathrm{K}) \\
(200 \mathrm{~ns})\end{array}$ & $\begin{array}{l}\mathrm{T}(\mathrm{K}) \\
(1 \mu \mathrm{s})\end{array}$ & $\begin{array}{l}\mathrm{T}(\mathrm{K}) \\
(3 \mu \mathrm{s})\end{array}$ & $\begin{array}{l}\mathrm{T}(\mathrm{K}) \\
(3 \mathrm{~ms})\end{array}$ \\
\hline 2.0 & 1398.9 & 1082.9 & 362.2 & 339.1 & 339.0 \\
2.4 & 1608.0 & 1228.8 & 375.1 & 347.8 & 347.3 \\
2.8 & 1798.2 & 1389.0 & 390.2 & 357.9 & 355.8 \\
3.2 & 1959.5 & 1532.4 & 403.0 & 366.4 & 363.7 \\
3.6 & 2117.1 & 1648.9 & 414.9 & 374.2 & 370.8 \\
\hline
\end{tabular}

\subsection{Ten pulse irradiation}

Fig. 3 shows the estimated back surface temperature vs. time of a wafer irradiated with 10 pulses of energy at 2.4 $\mathrm{mJ} /$ pulse (a), $3.2 \mathrm{~mJ} /$ pulse (b). The dash line in this figure indicates the melting temperature of $\mathrm{Si}$ at $1690 \mathrm{~K}$. It can be seen that when irradiated with a train of $2.4 \mathrm{~mJ}$ pulses, it takes a minimum of 3 pulses for the wafer to reach the melting temperature. In contrast, the wafer irradiated at 3.2 $\mathrm{mJ} /$ pulse remains at the melting temperature for the increasing time with each pulse delivered by the laser.

The maximum temperature induced with 10 pulses of 3.2 $\mathrm{mJ} /$ pulse is $2390 \mathrm{~K}$, which significantly exceeds the melting threshold of Si.
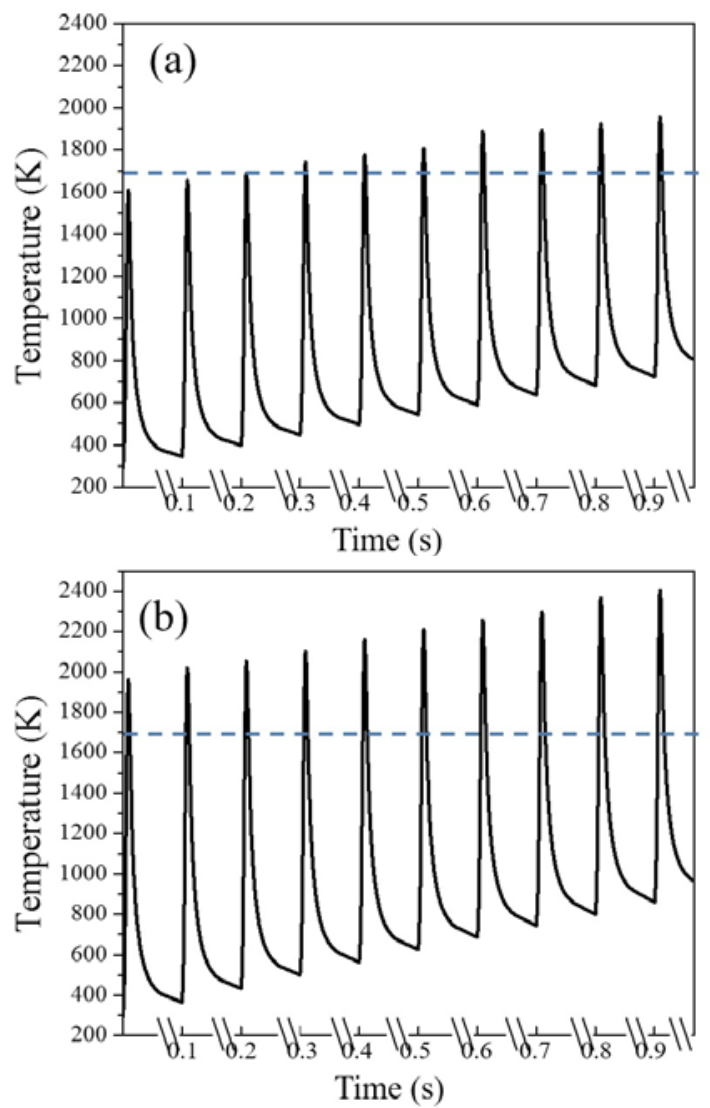

Fig. 3 Temperature of the back surface of Si vs. time induced with 10 pluses of an Nd:YAG laser delivering $2.4 \mathrm{~mJ} /$ pulse (a) and 3.2 $\mathrm{mJ} /$ pulse (b). The dash line indicates the melting temperature of $\mathrm{Si}$ at $1690 \mathrm{~K}$. 


\section{Results and discussions}

\subsection{Surface morphology modification of Si irradiated with 10 pulses of the $\mathrm{Nd}$ :YAG laser}

A microscopic image of the front surface of the Si sample irradiated with 10 pulses of the Nd:YAG laser delivering 3.2 $\mathrm{mJ} /$ pulse is shown in Fig. 4(a). It can be noticed that, consistent with the calculated temperature profiles, no visible damage has been induced to this material. In contrast, a significant surface modification has been observed on the back surface of samples irradiated with a train of 10 pulses of energy $2.4,2.8$ and $3.2 \mathrm{~mJ} /$ pulse, as shown by microscopic images in Fig. 4(b), (c) and (d), respectively. A series of DEKTAK line scans associated with these figures illustrate qualitatively the extent of laser-induced zones of swollen material. It can be seen that they extend from 90 to $200 \mu \mathrm{m}$ for laser pulse energy increasing from 2.4 to $3.2 \mathrm{~mJ} / \mathrm{pulse}$, while the maximum height of the swollen material increased from near 2 to almost $4 \mu \mathrm{m}$ for the same pulse energy range. No visible laser induced damage to the front surface was observed for all processed samples. A DEKTAK reference scan of the front surface of a sample irradiated with 10 pulses at $3.2 \mathrm{~mJ} /$ pulse indicates that the amplitude of roughness fluctuation is below $0.1 \mu \mathrm{m}$ in height. The imperfect overlapping of laser spots during the 10-pulse irradiation, which most likely is related to microscopic displacements of samples not physically immobilized on the X-Y-Z stage, seems responsible for the observed irregular extensions of the laser affected zones, especially observed for samples irradiated with pulses at 2.8 and $3.2 \mathrm{~mJ} /$ pulse.

To reveal cross-section of laser-irradiated sites, the samples were cleaved along a line crossing the site of interest. Fig. 5 (a) shows a cross section SEM image of Si site irradiated with 10 pulses at $2.8 \mathrm{~mJ} /$ pulse. It can be seen that the width of a damaged zone is around $140 \mu \mathrm{m}$, consistent with the result shown in Fig. 4 (c). A zone of the swollen material could be observed in this case. This is most likely due to the laser-induced melting and re-solidification of $\mathrm{Si}$ [23]. However, it is also possible that some material was ejected during this process and re-deposited in the Si surface [24]. The material ejection from molten $\mathrm{Si}$ has been documented with mass spectroscopy $[25,26]$ and some SEM supported data, similar to that shown in Fig. 5 (a), have reported that Nd:YAG laser ejected $\mathrm{Si}$ could piled up on the surface near the irradiated sites [24]. Fig. 5 (b) shows a cross section SEM image of the same sample after it was immersed in a $\mathrm{KOH}$ solution for 25 minutes at $30^{\circ} \mathrm{C}$. It can be seen that the etching procedure has revealed a selectively removed $28.3 \mu \mathrm{m}$ deep crater extending over a $190-\mu \mathrm{m}$ distance. This result is consistent with a selective area $\mathrm{KOH}$ etching of laser modified Si reported by Ito et al. [16], as well as with a study of the mechanisms driving laser assisted chemical etching of Si [27].
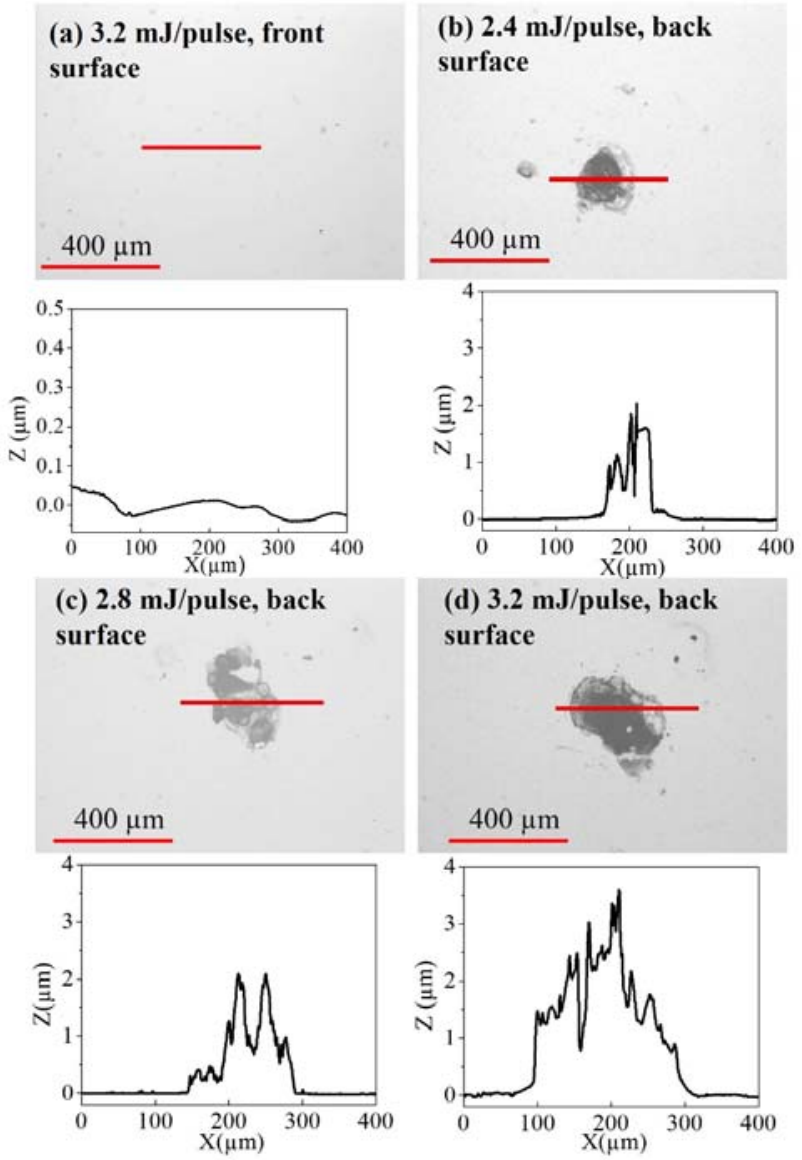

(d) $3.2 \mathrm{~mJ} /$ pulse, back surface

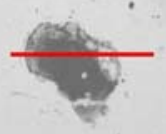

$400 \mu \mathrm{m}$

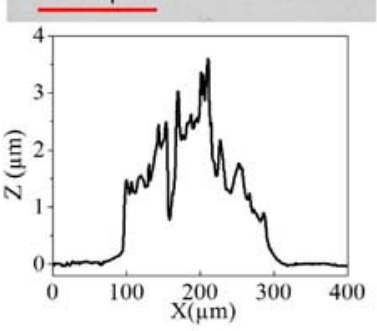

Fig. 4 Microscopic image of the front surface of a Si sample irradiated with a train of 10 pulses, $3.2 \mathrm{~mJ}$ each, focused on the back surface of the sample (a), and images of back surfaces irradiated with 10 pulses at 2.4 (b), 2.8 (c) and 3.2 (d) $\mathrm{mJ} /$ pulse. The associated DEKTAK scans illustrate accumulation of swollen material on the back surface.

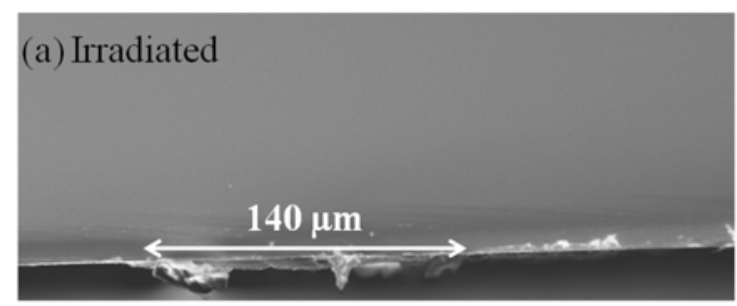

(b) Irradiated and $\mathrm{KOH}$ etching

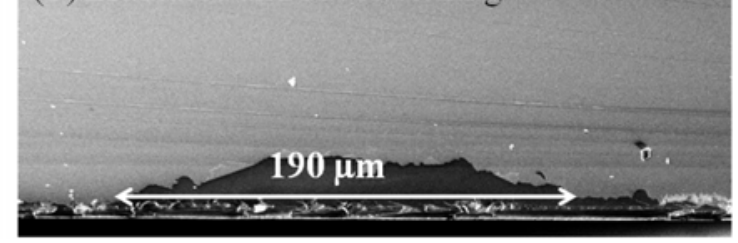

Fig. 5 Cross-section SEM images of Si irradiated with 10 pulses of an Nd:YAG laser at $2.8 \mathrm{~mJ} /$ pulse (a), and etched in a $\mathrm{KOH}$ solution for 25 minutes at $30^{\circ} \mathrm{C}($ b) 
JLMN-Journal of Laser Micro/Nanoengineering Vol. 11, No. 2, 2016

\subsection{Chemical modifications of Si induced by Nd:YAG laser with 10 pulses}

FTIR measurements were carried out to investigate $\mathrm{Si}$ chemical modification during Nd: YAG laser irradiation. Fig. 6 (a) shows the optical image of the Si sample back surface irradiated with a train of 10 pulses at $2.8 \mathrm{~mJ} /$ pulse focused on that surface. For the purpose of illustrating the effect of laser irradiation on the chemistry of $\mathrm{Si}$, we carried out FTIR transmission measurements for a series of spots along a line crossing one of the laser irradiated sites (indicated with a number from 1 to 10). The laser irradiation region (indicated with a red circle) shows obvious back surface morphology modification. Fig. 6 (b) shows the FTIR transmission spectra of different regions of laser irradiated $\mathrm{Si}$ sample. The numbers (from 1 to 10) in FTIR spectra (b) indicate that the spectrum is attributed to the circle site in microscopic image (a) marked with same value. As the silicon oxide (silica) wavelength peak is always reported to be $<1300 \mathrm{~cm}^{-1}$, the FTIR spectra were illustrated in the range of $800 \mathrm{~cm}^{-1}-1300$ $\mathrm{cm}^{-1}$ [28-30]. It shows that the shape of the spectra is different from non-irradiated sites (e.g. 1,2) to the irradiated ones (e.g. 5, 6, 7). The high absorbance peak around 1100 $\mathrm{cm}^{-1}$ indicates the presence of silicon oxides on the surface. The peak position shifted from $1108 \mathrm{~cm}^{-1}$ (red dash line) to $1070 \mathrm{~cm}^{-1}$ (green dash line), as shown in Fig. 6 (b), which is possibly due to porosity change in $\mathrm{Si}$ [31]. The absorbance in low frequency region $\left(\leq 900 \mathrm{~cm}^{-1}\right)$ is assigned to oxidized hydride deformation mode, $-\mathrm{O}_{\mathrm{y}} \mathrm{Si}-\mathrm{H}_{\mathrm{x}}$ [29]. The front surface on laser-irradiated sites is expected to be chemically stable, as their temperature remains well below the temperature threshold $(873 \mathrm{~K})$ for breaking $\mathrm{Si}-\mathrm{Si}$ bonds in an air environment [30].

The FTIR spectra of (a) non-irradiated (Spot No 1) and (b) irradiated Si (Spot No 5) have been fitted with Gaussian curves according to reference [30], as shown in Fig. 7. The peak around $870 \mathrm{~cm}^{-1}$ originates from $-\mathrm{O}_{\mathrm{y}} \mathrm{Si}-\mathrm{H}_{\mathrm{x}}$ and the peak at $970 \mathrm{~cm}^{-1}$ originates from $\mathrm{Si}-\mathrm{OH}$, while the peak at 1231 $\mathrm{cm}^{-1}$ is attributed to the $\mathrm{Si}-\mathrm{N}-\mathrm{Si}$. The modes covered from $1000 \mathrm{~cm}^{-1}$ to $1200 \mathrm{~cm}^{-1}$ are assigned to various $\mathrm{SiO}_{\mathrm{x}}$ species [29, 31], with the peak around $1150 \mathrm{~cm}^{-1}$ assigned to longitudinal optical (LO) mode of $\mathrm{Si}-\mathrm{O}-\mathrm{Si}$, and the peak at $1040 \mathrm{~cm}^{-1}$ to transverse optical (TO) mode of Si-O-Si. The peak at $1108 \mathrm{~cm}^{-1}$ is assigned to $\mathrm{Si}-\mathrm{O}-\mathrm{Si}$ stretching mode originated from single crystal $\mathrm{Si}$ oxidation, while the peak around $1070 \mathrm{~cm}^{-1}$ originates from Si-O-Si stretching mode of oxidized porous Si [29]. The intensity ratio of the porous $\mathrm{Si}$ oxide to the crystal Si oxide peaks increased from 0.36 on the non-irradiated to 6.47 on the irradiated site. The increased Si porosity in the laser irradiated zone is related to the laser induced heat effects $[29,30]$. Due to laser-induced material ejection [32] and re-solidification [23], a significant concentration of voids is generated in the processed material, promoting formation of the increased porosity of Si. This modified material is preferentially etched in the $\mathrm{KOH}$ solution, as shown in Fig. 5 (b). (a)

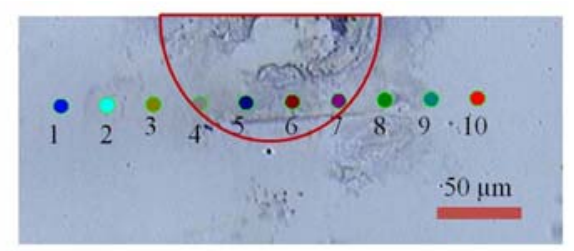

(b)

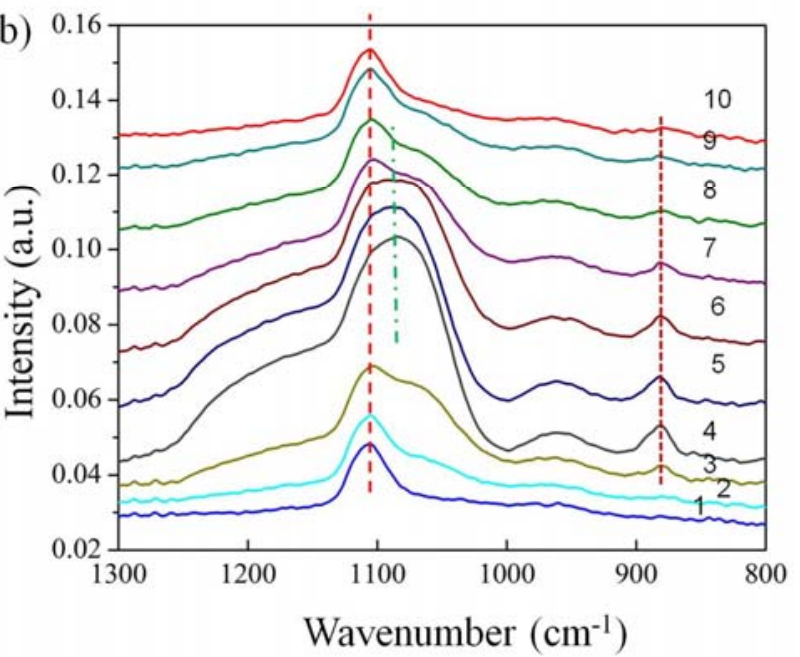

Fig. 6 (a) Optical image of Si back surface exposed in air to 10 pulses of an Nd:YAG laser at $2.8 \mathrm{~mJ} /$ pulse, and (b) FTIR transmission spectra of sites 1 to 10 as defined in Fig. 6 (b). The appearance of a short-wavenumber shoulder at $1070 \mathrm{~cm}^{-1}$ is related to the formation of porous Si oxides.

These results indicate that Nd:YAG laser processing of $\mathrm{Si}$ wafers is feasible for melting of their back surface, without inducing measurable changes to their front surface morphology and chemistry. The method has the potential for fusing $\mathrm{Si}$ wafers with $\mathrm{Si}$, or with other materials important for microelectronic packaging and integration with, e.g., biocompatible materials. The Nd:YAG laser irradiation of the back surface of $\mathrm{Si}$ in air leads to formation of an oxidized, porous layer of material that could be removed relatively easily with a $\mathrm{KOH}$ solution. 
JLMN-Journal of Laser Micro/Nanoengineering Vol. 11, No. 2, 2016

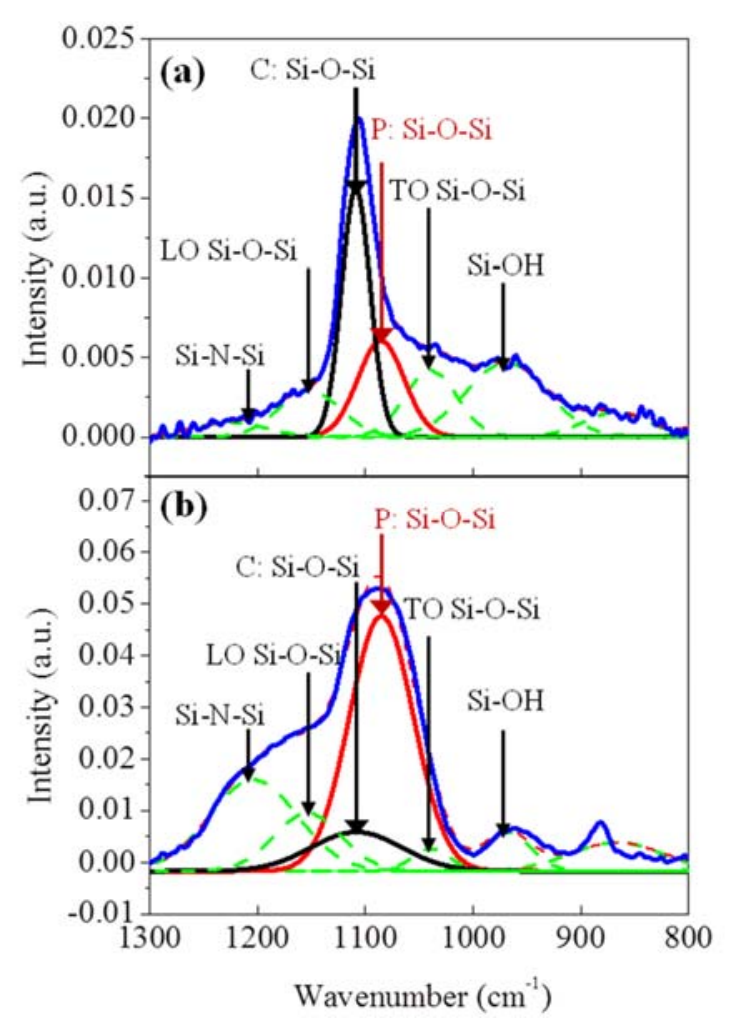

Fig. 7 FTIR spectra of (a) non-irradiated and (b) irradiated sites fitted with Gaussian curve.

\section{Summary and discussions}

We have investigated processing of $380 \mu \mathrm{m}$ thick $\mathrm{Si}(001)$ wafers with a pulsed Nd:YAG laser $(\lambda=1064 \mathrm{~nm}, \tau=112$ ns) beam focused to a $100 \mu \mathrm{m}$ spot on the back surface of the wafers. Computer modeling suggests that melting of the back surface $(1690 \mathrm{~K})$ can be achieved with a train of 4 pulses of energy at $2.4 \mathrm{~mJ} /$ pulse, while the same temperature could be induced with just 1 pulse of energy at $3.2 \mathrm{~mJ} /$ pulse. The significantly modified surface morphology (swelling) of wafers processed in air with 10 pulses at $2.4,2.8$ and 3.2 $\mathrm{mJ} /$ pulse has been observed with DEKTAK profiling and cross-sectional SEM images. The swelling is consistent with a transition of the crystalline phase of $\mathrm{Si}$ into an oxidized, amorphous Si. Formation of a chemically modified Si has been confirmed by FTIR absorption spectroscopy. Selectivearea melting of back surface of $\mathrm{Si}$ wafers with an Nd:YAG laser offers a potentially cost-attractive method for packaging of advanced microelectronic/photonic devices. The investigated method could also be employed for micromachining of back surface of Si wafers exposed in air or atmospheres of other gases designed specifically for selective area etching of this material.

\section{Acknowledgements}

This work was supported by the Natural Science and Engineering Research Council of Canada Discovery Grant
No. 122795-2010 and the program of the Canada Research Chair in Quantum Semiconductors.

\section{Reference}

[1] C. Luo and L. Lin: Sensor. Actuat. A Phys. 97-98, (2002) 398.

[2] Y. F. Chong, K. L. Pey, a. T. S. Wee, M. O. Thompson, C. H. Tung and a. See: Appl. Phys. Lett. 81, (2002) 3786.

[3] D. Giubertoni, G. Pepponi, M. A. Sahiner, S. P. Kelty, S. Gennaro, M. Bersani, M. Kah, K. J. Kirkby, R. Doherty and M. A. Foad: J. Vac. Sci. Technol. B Microelectron. Nanom. Struct. 28, (2010) C1B1.

[4] C. H. Poon, B. J. Cho, Y. F. Lu, M. Bhat and A. See: J. Vac. Sci. Technol. B Microelectron. Nanom. Struct. 21, (2003) 706.

[5] M.-J. Bañuls, R. Puchades and Á. Maquieira: Anal. Chim. Acta $777,(2013) 1$.

[6] B. N. Johnson and R. Mutharasan: Biosens. bioelectron. 32, (2012) 1 .

[7] N. Liu, W. M. Hassen and J. J. Dubowski: Appl. Phys. A $117,(2014) 37$.

[8] N. Liu, X. Huang and J. J. Dubowski: J. Phys. D: Appl. Phys. 47, (2014) 385106.

[9] N. Liu, K. Moumanis and J. J. Dubowski: JoVE (2015) e52720.

[10] A. Wissinger, A. Olowinsky, A. Gillner and R. Poprawe: Microsyst. Technol. 19, (2013) 669.

[11] E. Haberstroh, W.-M. Hoffmann, R. Poprawe and F. Sari: Microsyst. Technol. 12, (2006) 632.

[12] S. Theppakuttai, D. B. Shao and S. C. Chen: J. Manuf. Process. 6, (2004) 24.

[13] M. Kumagai, N. Uchiyama, E. Ohmura, R. Sugiura, K. Atsumi and K. Fukumitsu: IEEE Trans. Semicond. Manuf. 20, (2007) 259.

[14] E. Ohmura, Y. Kawahito, K. Fukumitsu, J. Okuma and H. Morita: J. Mater. Sci. Eng. A 1, (2011) 46.

[15] M. Birkholz, M. Kaynak, T. Semperowitsch, B. Holz and S. Nordhoff: J. Optoelectron. Adv. Mater. 12, (2010) 479. [16] Y. Ito, H. Sakashita, R. Suzuki, M. Uewada, K. P. Luong and R. Tanabe: JLMN 9, (2014) 98.

[17] E. Ohmura, F. Fukuyo, K. Fukumitsu and H. Morita: Int. J. Comput. Mater. Sci. Surf. Eng. 1, (2007) 677.

[18] R. Stanowski, O. Voznyy and J. J. Dubowski: JLMN 1, (2006) 17.

[19] G. E. Jellison and D. H. Lowndes: Appl. Phys. Lett. 51, (1987) 352.

[20] K. Svantesson and N. Nilsson: J. Phys. C: Solid State Phys. 12, (1979) 3837.

[21] M. Darif, N. Semmar and F. Orléans Cedex Proceedings of the COMSOL Conference 2008 Hannover (2008) 1.

[22] J. R. Chelikowsky and M. L. Cohen: Phys. Rev. B 14, (1976) 556.

[23] S. Dauer, A. Ehlert and S. Büttgenbach: Sensor Actuat. A: Phys. 76, (1999) 381.

[24] D. J. Lim, H. Ki and J. Mazumder: J. Phys. D: Appl. Phys. 39, (2006) 2624. 
[25] V. Craciun: Appl. Phys. Lett. 79, (2001) 442.

[26] W. Marine, N. M. Bulgakova, L. Patrone and I. Ozerov:

J. Appl Phys. 103, (2008) 094902.

[27] K. W. Kolasinski, D. Mills and M. Nahidi: J. Vac. Sci. Technol. A Vacuum, Surfaces, Film. 24, (2006) 1474.

[28] E. R. Lippincott, a. Vanvalkenburg, C. E. Weir and E. N. Bunting: J. Res. Natl. Bur. Stand. 61, (1958) 61.

[29] D. B. Mawhinney, J. A. Glass and J. T. Yates: J. Phys. Chem. B 5647, (1997) 1202.

[30] G. E. a. Swann and S. V. Patwardhan: Clim. Past 7, (2011) 65

[31] N. Posseme, T. Chevolleau, T. David, M. Darnon, O. Louveau and O. Joubert: J. Vac. Sci. Technol. B Microelectron. Nanom. Struct. 25, (2007) 1928.

[32] R. Laiho and a. Pavlov: Thin Solid Film 255, (1995) 9.

(Received: February 5, 2016, Accepted: May 30, 2016) 